\title{
A typology of loss and damage perspectives
}

Article

Accepted Version

Boyd, E., James, R. A., Jones, R. G., Young, H. R. and Otto, F. E. L. (2017) A typology of loss and damage perspectives. Nature Climate Change, 7. pp. 723-729. ISSN 1758-678X doi: https://doi.org/10.1038/nclimate3389 Available at https://centaur.reading.ac.uk/81728/

It is advisable to refer to the publisher's version if you intend to cite from the work. See Guidance on citing.

To link to this article DOI: http://dx.doi.org/10.1038/nclimate3389

Publisher: Nature Publishing Group

All outputs in CentAUR are protected by Intellectual Property Rights law, including copyright law. Copyright and IPR is retained by the creators or other copyright holders. Terms and conditions for use of this material are defined in the End User Agreement.

\section{www.reading.ac.uk/centaur}

\section{CentAUR}

Central Archive at the University of Reading

Reading's research outputs online 


\section{A typology of loss and damage perspectives}

2 Emily Boyd ${ }^{a, b *}$, Rachel A. James ${ }^{c, d}$, Richard G. Jones ${ }^{e, f}$, Hannah R. Young ${ }^{g}$,

3 Friederike E. L. Otto ${ }^{\mathrm{C}}$

4

5 aDepartment of Geography and Environmental Science, University of Reading, UK

$6 \quad{ }^{\mathrm{b}}$ Lund University Centre for Sustainability Studies, Sweden

$7 \quad{ }^{\mathrm{c} E n v i r o n m e n t a l}$ Change Institute, University of Oxford, UK

$8 \quad{ }^{\mathrm{d}}$ Department of Oceanography, University of Cape Town, South Africa

$9 \quad{ }^{\mathrm{e}}$ Met Office Hadley Centre, UK

10 fSchool of Geography and Environment, University of Oxford, UK

$11{ }^{9}$ Department of Meteorology, University of Reading, UK

12

$13{ }^{*}$ corresponding author: emily.boyd@lucsus.lu.se

14 
Loss and Damage (L\&D) has been the subject of contentious debate in international climate policy for several decades. Recently, formal mechanisms on L\&D have been established, but arguably through unclear language. This ambiguity is politically important, but researchers and practitioners require clearer understandings of L\&D. Here we report on the first in-depth empirical study of actor perspectives, including interviews with 38 key stakeholders in research, practice, and policy. We find points of agreement and also important distinctions in terms of: the relationship between L\&D and adaptation, the emphasis on avoiding versus addressing L\&D, the relevance of anthropogenic climate change, and the role of justice. A typology of four perspectives is identified, with different implications for research priorities and actions to address L\&D. This typology enables improved understanding of existing perspectives and so has potential to facilitate more transparent discussion of the options available to address L\&D. 
The L\&D issue has its origins in calls from Small Island Developing States (SIDS) for compensation for climate change impacts, particularly sea level rise $\mathrm{e}^{1,2}$. It is often characterised as a highly political, contentious and polarised debate between developed and developing countries ${ }^{1,3}$. In recent years, however, agreements have been made between parties, and L\&D has become a formal part of the United Nations Framework Convention on Climate Change (UNFCCC), with the establishment of the Warsaw International Mechanism (WIM), in $2013^{4}$, and the more recent Paris Agreement ${ }^{5}$, which established a separate article on L\&D, and ensured the continuation of the WIM. Arguably, these political agreements have been made possible through ambiguous language ${ }^{6}$, and it is not clear from UNFCCC decisions exactly what $L \& D$ signifies. There is no formal definition of $L \& D$, and there have been no official discussions about what the term means ${ }^{7}$.

Now, attention is also being given to implementation. The WIM has an Executive Committee (ExCom), with a mandate to explore implementation of approaches to address $L \& D^{8}$; and the science-practice-policy community, including adaptation and disaster risk practitioners, from non-governmental organisations, consultancies, UN agencies, and development banks, are looking for ways to understand and address $L \& D^{9-12}$. There has also been a substantial growth in the number of academic papers referring to $L \& D^{13-16}$ (see supplementary figure 1 ). All of these emerging actors engaging in L\&D discussions may have different perspectives on L\&D; and certainly several have highlighted the lack of clarity surrounding $L \& D^{13,17}$. There have been some efforts to develop working definitions ${ }^{9,18,19}$ and frameworks ${ }^{20,21}$, however these still leave room for different interpretations. For example, one UNFCCC literature review defined L\&D as "the actual and/or potential manifestation of impacts associated with climate change in developing countries that negatively affect human and natural systems" ${ }^{\prime 22}$. This leaves some important questions about L\&D open ${ }^{7}$, 
57 including how actions to address L\&D might be distinct from existing adaptation,

67

disaster risk reduction (DRR), development and humanitarian work ${ }^{23,24}$.

Therefore, whilst there are good reasons for ambiguity in the political domain ${ }^{6}$, moving from negotiations to implementation, greater clarity may prove to be important. This does not imply that all emerging stakeholders must agree on one definition of L\&D, but that they may benefit from understanding the range of viewpoints that already exist, and that inform current practice. By making implicit definitions visible, more informed discussion around options to address L\&D might be facilitated.

Previous work has characterised party positions on $L \& D^{2,3,25}$, and analysed L\&D framings and discourses in UNFCCC documents and discussions ${ }^{1,6}$. Here we draw on social science and co-production approaches to deliver an empirical, transdisciplinary study of L\&D perspectives from a range of stakeholders across science, practice and policy (UNFCCC negotiators and policy-makers, and researchers and practitioners with expertise in adaptation, DRR, law, climate science, philosophy, and economics). The analysis is based on interviews (conducted between April and November 2015) with 38 stakeholders, systematically sampled to represent diverse backgrounds, and promote gender and regional balance (see Methods for details on sampling strategy).

Interviewees were asked about the meaning of L\&D, and how it should be addressed. The data were anonymised, and analysed to identify a "typology" of perspectives on L\&D that was iteratively refined through analysis of literature, including UNFCCC decision texts, and sustained engagement with core communities working on L\&D, including feedback discussions with expert groups, notably at the third meeting of the 
ExCom of the WIM (see Methods). We present the typology, and explore the implications for practice, policy and research.

\section{Typology of perspectives}

We identify a spectrum of four L\&D perspectives (Figure 1a). The perspectives do not necessarily have associated definitions, but represent consistent viewpoints about what L\&D means and how to address it. We found that the term "loss and damage" was not used consistently, sometimes being used to refer to impacts, and sometimes to describe a mechanism or debate.

\section{Adaptation and mitigation perspective}

Some stakeholders highlight all anthropogenic climate change impacts as potential L\&D, and stress that the UNFCCC's mandate is to avoid dangerous anthropogenic interference, or L\&D from climate change, for example stating "the loss and damage issue triggered the entire convention" (interviewee 14, 2015). The UNFCCC already has mechanisms for adaptation and mitigation, and this perspective implies that these existing efforts are sufficient to prevent L\&D. Stakeholders can express confusion at the call for L\&D mechanisms which are separate from adaptation, or suggest that distinctions between adaptation and L\&D are false or politically motivated. As noted by one stakeholder: "it's hard to argue a differentiation between loss and damage and adaptation or disaster risk management" (interviewee 13, 2015). 
108 For other stakeholders, new initiatives and discussions around L\&D represent an

109 opportunity to work towards comprehensive risk management by building on existing 110 efforts under DRR, climate change adaptation, and humanitarian work. In the words

111 of one stakeholder: "we need to take a holistic approach, linking these ongoing

112 initiatives together with sustainable development and DRR and climate change

113 resilience building" (interviewee 33, 2015). Managing L\&D could include approaches

114 to risk reduction, risk retention, and risk transfer, including those which go beyond the

115 national level, and address high level risks (consistent with $\operatorname{ref}^{26}$ ). The perspective

116 focuses on a techno-pragmatic problem approach. Separating L\&D which can and

117 cannot be adapted to is perceived as unhelpful, for example: "if you start to have

118 policy processes at the national level, which treat $L \& D$ and adaptation as separate,

119 you lose the opportunity to manage it properly" (interviewee 35, 2015).

121 Limits to adaptation perspective

122 This perspective on L\&D is centred around the limits to adaptation, and residual L\&D

123 beyond mitigation and adaptation. L\&D generally applies to impacts of any climate-

124 related event, rather than just those that can be attributed to climate change ${ }^{9,18}$. The

125 focus is on vulnerability, and on the most vulnerable who are already perceived to be

126 suffering L\&D. As one stakeholder explained: "let's say there's a [crop] failure and we

127 don't have enough to eat... Households are not passive, they react... cutting the

128 corners on calories, typically mothers will eat less. Over the long term, 900 calories a

129 day is not sustainable for the human body... Those little gaps at some point start

130 looking like L\&D" (interviewee 18, 2015). This perspective draws on existing literature

131 on Limits to Adaptation, which, although contentious, has become mainstream within 
132 adaptation discussions ${ }^{27}$, including in the Intergovernmental Panel on Climate 133 Change (IPCC) Working Group II report ${ }^{28}$.

134

135 Existential perspective

136 For some, L\&D represents a means to highlight the importance of addressing the

137 inevitable harm which climate change will impose on vulnerable countries,

138 populations, cultures, and ecosystems: "harm is occurring, something needs to be

139 done about it" (interviewee 30, 2015). This perspective is "existential" in the sense

140 that climate change represents unavoidable transformation for some communities

141 and systems. There is an emphasis on irreversible loss, non-economic losses

142 (NELs), justice and responsibility. There is a sense of urgency to provide options for

143 those who are most vulnerable, for example through migration facilities; and there is

144 also discussion of compensation, whether monetary or non-monetary: "It has ... an

145 element of compensation whether it's financial or other" (interviewee 30, 2015).

146

147

\section{Points of agreement and distinction}

149 Stakeholders agreed that L\&D mechanisms should refer to both slow onset events

150 and extreme events ${ }^{22}$, consistent with UNFCCC policy documents ${ }^{4,5,29}$ and scientific

151 literature ${ }^{13,17}$. There was also some commonality across the interviews in terms of

152 whether L\&D mechanisms should be "ex-ante" or "ex-post". When asked whether

153 L\&D mechanisms should aim to prevent "potential L\&D" or address "actual L\&D",

154 most stakeholders agreed that both were important, however there was a difference

155 in terms of emphasis. 
157 Within each perspective, distinct words and phrases (see Table 1) were found to be 158 frequently used or emphasised by interviewees when describing L\&D (see Methods).

159 There is some inevitable overlap in terminology, but there is sufficient distinction in

160 key words to provide an important illustration of the divergence of understandings of

161 L\&D. For example, some stakeholders speak more about "preventing" "potential

162 L\&D", or ex-ante measures, and some highlight the need for approaches to address

163 actual, "unavoidable", L\&D, or "ex-post" measures.

164

165 In Figure 1b, the ex-ante to ex-post axis (blue arrow) is displayed alongside an axis

166 illustrating the distance from adaptation and existing mechanisms (black arrow).

167 Current UNFCCC architecture is arguably focused on ex-ante measures, and the

168 Adaptation and Mitigation perspective would imply that these are sufficient to address

169 L\&D; whereas the Existential perspective highlights the need for additional, ex-post

170 actions. This contrast can be observed between a quote from one stakeholder when

171 referring to the WIM: "A huge part of what we are supposed to be doing is figuring out

172 how to reverse and revert $L \& D$ " (interviewee 31, 2015), and another: "L\&D policy

173 responses are not about preventing these impacts, they are not about trying to make

174 the risk of negative impacts small" (interviewee 19, 2015). The other perspectives lie

175 somewhere between, with Risk Management, for example, placing value on

176 comprehensive approaches which consider ex-ante and ex-post action together.

177

178 There are also differences in the spatial scale at which losses and damages are

179 described, represented by the purple arrow. Risk Management largely focuses on

180 global or national level analysis of risk, whereas Limits to Adaptation highlights

181 impacts at the local or community scale. The blue shading indicates differences in

182 the relevance of climate change. For the Adaptation and Mitigation and Existential

183 perspectives, L\&D is about anthropogenic climate change, whereas Limits to 
184

185

186

187

188

189

190

191

192

193

194

195

196

197

198

199

200

201

202

203

204

205

206

207

208

209

Adaptation and Risk Management highlight the importance of dealing with all climaterelated risks, for example: "the more urgent issue is... actually... responding to or adapting to extreme weather events, whether it's caused by people or not" (interviewee 34, 2015).

The grey dashed contours refer to the emphasis on justice. For the Existential perspective, questions of justice and responsibility are emphasised, and for some central. For example one stakeholder describes the goal of the L\&D mechanisms as "to get some sort of equity between different nations and generations" (interviewee 29, 2015), and another said "it's about recognition that we have responsibility" (interviewee 30,2015$)$. They view L\&D as a way "to address the uneven power balance that currently exists under the current negotiations" (interviewee 30, 2015). Several are quite specific that it is a "polluter pays" issue. This does not imply that the other perspectives are not based on principles of justice: there is some explicit mention of distributive justice in connection with risk management approaches ${ }^{20}$ and different ethical framings for L\&D have been discussed ${ }^{30,31}$. However, during the interviews there was generally little discussion of justice in connection with the other perspectives.

\section{Action, research and finance for loss and damage}

Stakeholders were asked what kind of practical actions and scientific research would be needed to address L\&D. We analysed the logical implications of each perspective for action, science, and financing; making inferences about appropriate tools for each perspective (Table 2). 


\section{Action}

211 The Adaptation and Mitigation perspective suggests that L\&D should be dealt with

212 through existing mechanisms, and therefore does not imply distinct actions to

213 address L\&D. The Risk Management perspective emphasizes a whole suite of risk

214 management tools. The Limits to Adaptation perspective typically highlights

215 participation, and favours actions associated with development interventions such as

216 informal social protection mechanisms, micro insurance, innovations in livelihood,

217 and early warning systems. The Existential perspective places more emphasis on ex-

218 post measures, including, more controversially, compensation and in some cases

219 litigation, but also other measures including resettlement.

220

221 There are some tools which are referred to by many stakeholders with different views

222 about L\&D, for example insurance. However, there may be distinctions in what is

223 meant by this; as one stakeholder highlights: "when I say insurance, there's going to

224 be a payout around 6-9 months in the season after you pay your premium... when

225 other people talk about insurance, [they are asking] "where am I going to move my

22625000 island population to resettle" (interviewee 34, 2015). Mace and Verheyen

227 (2016) suggest that in the UNFCCC context "insurance" has been used by AOSIS for

228 decades, "somewhat euphemistically", to refer to mechanisms that might provide

229 compensation, whereas developed countries prefer to highlight more traditional forms

230 of insurance. Further work is needed to establish what kinds of insurance are

231 relevant, how they combine with other actions to address $L \& D$, and to identify cases

232 where insurance is not a suitable solution ${ }^{32}$.

233

234

235 
236 For practitioners, the ambiguity surrounding L\&D may be challenging for

237 implementation, as highlighted by one stakeholder: "We can talk about $L \& D$ in

238 conceptual or theoretical level, but when it boils down to operations, it is quite

239 challenging with no definition" (interviewee 33, 2015). Without agreement on how to

240 define L\&D, it might prove difficult to measure the effectiveness of projects,

241 programmes and activities on the ground.

242

243

Research

244 When asked about science relevant to support L\&D mechanisms, almost every

245 interviewee had a different answer, highlighting both the large number of research

246 gaps in this field and the diversity of views. Many stakeholders mentioned

247 attribution science at least partly due to their awareness of our own previous work on

248 extreme event attribution ${ }^{7,33,34}$. There was variation between interviewees in terms of

249 their understanding of this science: some referred to specific forms of attribution

250 science or even specific academic papers, whereas others were broadly referring to

251 the concept of attributing causality. There was also variation in opinion about whether

252 attribution is useful for L\&D, consistent with previous findings ${ }^{14}$. The most common

253 comment was to express caution about uncertainties in attributing specific losses to

254 anthropogenic climate change and/or the controversy of such findings, and an

255 emphasis that this should not delay action to support vulnerable people, for example:

256 "We should worry about how to deal with this, let's not worry about whether it's

257 caused by humans" (interviewee 28, 2015). This kind of emphasis was quite

258 consistent across the perspectives.

259

260 The Adaptation and Mitigation perspective does not imply new research questions to

261 understand L\&D, additional to those which inform adaptation and mitigation. The Risk 
Management perspective highlights understanding how climate change influences existing risk, as one stakeholder explained: " $L \& D$ is what happens as a result of the combination of existing vulnerability plus changing risk profile that climate change brings" (interviewee 35, 2015). Analysis is needed to evaluate whether existing disaster risk assessments can address this evolving risk from climate change, and to identify gaps in risk management approaches. The Limits to Adaptation perspective highlights the importance of gathering empirical evidence from vulnerable people to understand their experiences of barriers to implementing adaptation and limits to its effectiveness. The emphasis on adaptation limits implies that adaptation monitoring and evaluation (M\&E) is also important. The Existential perspective places specific emphasis on permanent losses, which have received limited research attention to date. Relevant aspects may include new questions about NELs such as loss of homeland, livelihood, sovereignty, youthfulness, mental health and wellbeing, including "how loss is perceived and understood" (interviewee 30, 2015) (as also highlighted in recent academic papers ${ }^{35,36}$ ).

Science questions are not necessarily inconsistent across perspectives. For example, even if stakeholders argue that L\&D should be dealt with through adaptation and mitigation, they would likely still see the benefit of M\&E, which could identify areas where adaptation measures can be improved. Therefore, scientific progress is not inhibited by contrasting perspectives on L\&D. However, there are many potential research questions surrounding L\&D (only partly covered by Table 2) and it is unlikely that all can be answered. If science is to support policy, research-policy dialogue on L\&D is a necessary step to prioritise research needs. 
288 The interviewees were deliberately not asked about finance related to L\&D to judge 289 the extent to which this featured in their perception of the issue. Several interviewees 290 highlighted that there are others for whom financial support is key, for example:

291 "there are countries... who... see... that loss and damage is about attribution of 292 blame and taking compensation..." (interviewee 13, 2015), and "in the end it's about 293 who pays for what" (interviewee 25, 2015). This impression seems to be a key driver 294 of L\&D discussions, with fear of paying compensation perhaps the reason that many 295 associated terms are off-limits. One interviewee explained how a developed country 296 government was "not prepared to talk about climate change that causes permanent 297 losses" (interviewee 17, 2015).

298

299 Interestingly, none of the interviewees described their own position on L\&D in this 300 way. There were some who made the case for monetary compensation, associated 301 with the Existential perspective, but these stakeholders also highlighted that this was 302 not the only, or even the most important issue, for example: "The ultimate goal for 303 countries like St Lucia, can't be simply to get money for lost lives, that would be 304 terrible to say there's nothing we can do so let's just collect a premium for the 305 thousand people who just died" (interviewee 30, 2015). This is consistent with 306 statements made by developing country negotiators ${ }^{37}$.

308 Other interviewees did not say much about finance, perhaps due to the controversial 309 nature of this issue. In connection with Risk Management, there was some emphasis 310 on private sector funding, but otherwise little discussion about who would pay for the 311 actions to address L\&D. Financial instruments for L\&D do feature in the WIM 312 ExCom's initial two-year workplan, and were also the subject of a recent forum of the 313 Standing Committee on Finance ${ }^{38}$. However, this matter is largely unresolved, as 
314 illustrated in the indicative framework for the five-year rolling workplan of the ExCom, 315 which currently has a "placeholder for finance-related topics"8.

\section{Implications for policy}

319 For researchers and practitioners, characterising a spectrum of different perspectives

320 on L\&D has potential to help identify the real options available for addressing L\&D.

321 For UNFCCC policy-makers, however, there is an imperative for agreement and

322 convergence, and clarifying different perspectives could reopen discussions and stall

323 negotiations. So what does the typology of perspectives mean for progress in

324 international policy? What kind of stakeholders is each perspective associated with

325 and how do they relate to political positions and groupings? How far are the different

326 perspectives already represented in UNFCCC agreements?

328 Stakeholder groups were identified and mapped onto the typology in Figure 1c (see

329 Methods). One important finding is that there is not a simple polarization between

330 political actors from developed and developing countries, and stakeholders do not

331 neatly divide between the four perspectives. Many individuals express views which

332 encompass more than one perspective, and there are a few whose ideas about L\&D

333 did not resonate with any of them (largely those who focused on the lack of clarity

334 around L\&D, or who were highly skeptical of UNFCCC processes). In general, the

335 Adaptation and Mitigation perspective was associated with developed country

336 negotiators, and this is keeping with the proposals of Annex I countries during the

337 negotiations, specifically to have no separate article on L\&D in the Paris Agreement.

338 This is in contrast to the SIDS and Least Developed Country (LDC) positions ${ }^{25}$. We

339 interviewed several stakeholders who represent or advise these groups and their 
340 views encompassed elements of the Existential, Limits to Adaptation and Risk

341 Management perspectives. The clearest expressions of the Existential, Limits to

342 Adaptation, and Risk Management perspectives were from climate justice

343 campaigners, adaptation practitioners, and disaster risk reduction experts,

344 respectively.

345

346 The WIM and Paris Agreement texts were also analysed, and mapped onto the 347 typology in Figure 1c. The WIM text ${ }^{4}$ is ambiguous and all encompassing. For 348 example, the WIM is part of the Cancun Adaptation Framework and thus could be 349 regarded as consistent with the Adaptation and Mitigation perspective. However, the 350 WIM is also sufficiently vague that it does not rule out specific measures, and the 351 workplan includes terminology which is associated with each of the perspectives 352 (Table 1), for example "comprehensive risk management", "non-economic losses", 353 and "particularly vulnerable" 39 .

354

355 In the Paris Agreement and decision text ${ }^{5}$, the notion of L\&D is a little more tightly 356 constrained. For the first time L\&D is separated from adaptation in a separate article 357 (Article 8), which conflicts with some core aspects of the Adaptation and Mitigation 358 perspective. Conversely, the Paris decision text explicitly states (in paragraph 51) 359 that Article 8 does not involve liability and compensation, which implies that some 360 aspects of the Existential perspective are excluded. However, permanent and 361 irreversible losses are mentioned, which form a key component of the Existential 362 perspective. Vanhala and Hastbaek $^{6}$ also find increasing precision in the Paris text 363 relative to the WIM.

364

365 The WIM and Paris Agreement represent success in reaching consensus, and in 366 incorporating language which spans much of the typology of perspectives. So does 
367 this signal political convergence in terms of how to manage L\&D? Mace and 368 Verheyen ${ }^{2}$ argue that, from a legal perspective, the Paris text leaves "all options 369 open" for L\&D. They highlight that the structure, mandate, and effectiveness of the 370 WIM is currently quite limited: it is not a legal entity and does not have technical 371 advisory or financial functions. Therefore even if key words from each perspective 372 are referred to in the texts of the WIM and the Paris Agreement this does not 373 guarantee that sufficient actions will be implemented to address L\&D as conceived 374 under each perspective. Important questions remain about what actions will be 375 prioritised and who will be responsible for their implementation and financing.

377 Therefore, despite the imperative for convergence, characterizing the range of 378 perspectives might still be useful for policy-making. The typology reveals a complex 379 but rich array of knowledge, expertise and aspirations for L\&D, and could be useful in 380 three key ways. First, while it may not be desirable to openly acknowledge points of 381 disagreement within political negotiations, it is important that policy-makers are 382 aware of different perspectives. If different perspectives are not reflected in the 383 actions which are implemented to address L\&D, negotiations could re-emerge. The 384 typology might therefore be useful background information for policy-makers, 385 particularly those who are new to the L\&D discussions. Second, the typology 386 demonstrates some points of agreement and overlaps between stakeholder groups 387 (see Figure 1c). Whilst there are disagreements, we do not find evidence for a simple 388 polarization between those who seek compensation and those who wish to avoid 389 paying compensation. This finding implies potential for some aspects of the debate to be nuanced and depoliticised. The typology could be used to develop frameworks for 391 conceptualising L\&D, which incorporate priorities from multiple stakeholders and 392 identify a policy space for L\&D which is acceptable for different parties (and there 393 have been recent efforts to develop such a framework). ${ }^{20}$ 
395 Finally, the typology could facilitate more transparent and informed discussion 396 outside, or on the fringes of, the policy sphere, about the span of options available for 397 research and actions to address L\&D. These discussions might lead to research 398 findings and practical solutions which can later inform or be supported by UNFCCC 399 policy. For example, the typology could be used to identify research questions 400 associated with each perspective (informed by Table 2) as a basis for dialogue 401 between the ExCom and the IPCC on areas of science relevant to L\&D for 402 assessment in its upcoming reports.

403

404 Many of the questions over the meaning of L\&D are reminiscent of the long-standing 405 debate among adaptation scholars and practitioners of the need for clarity in what 406 adaptation means to effectively measure and implement adaptation ${ }^{40}$. The challenge 407 of reaching specificity in a contested policy space is not a new one, but, in identifying 408 a typology of perspectives of $L \& D$, we hope to fast track progress at an early stage of 409 L\&D policy development.

\section{References}

412 1. Calliari, E. Loss and damage: a critical discourse analysis of Parties' positions in 413 climate change negotiations. Journal of Risk Research, 1-23 (2016).

414 2. Mace, M. J. \& Verheyen, R. Loss, Damage and Responsibility after COP21: All 415 Options Open for the Paris Agreement. Review of European, Comparative \& 416 International Environmental Law 25, 197-214 (2016). 
417 3. Mace, M. J. \& Schaeffer, M. Loss and Damage in the UNFCCC: what relationship 418 to the Hyogo Framework? Climate Analytics http://www.lossanddamage.net/4941 419 (2013).

420 4. UNFCCC. Decision 2/CP.19: Warsaw international mechanism for loss and 421 damage associated with climate change impacts. (2013).

422 5. UNFCCC. Adoption of the Paris Agreement. FCCC/CP/2015/10/Add.1. Paris, 423 France. , 1-32 (2015).

424 6. Vanhala, L. \& Hestbaek, C. Framing Climate Change Loss and Damage in the 425 UNFCCC Negotiations. Global Environmental Politics, 111-129 (2016).

426 7. James, R. et al. Characterizing loss and damage from climate change. Nature 427 Climate Change 4, 938-939 (2014).

428 8. UNFCCC. Report of the Executive Committee of the Warsaw International 429 Mechanism for Loss and Damage associated with Climate Change Impacts $430 \mathrm{FCCC} / \mathrm{SB} / 2016 / 3,14$ October 2016 . (2016).

431 9. UNEP. Loss and Damage: The role of Ecosystem Services. United Nations 432 Environment Programme, Nairobi, Kenya (2016).

433 10. WFP Regional Bureau for Asia. Loss \& Damage: Repairing shattered lives. Paper 434 No. 1. March 2014. Black and White Paper Series.

435 11. CARE, Germanwatch, ActionAid, WWF. Loss and Damage: Into Unknown 436 Territory. 21 July 2012 . .

437 12. UNFCCC. Submissions on possible activities under strategic workstreams of the 438 five-year rolling workplan: Organizations. Submissions received as at 17 March 
439

440

441

442

443

444

445

446

447

448

449

450

451

452

453

454

455

456

457

458

459

460

2017. Available

at: http://unfccc.int/adaptation/groups_committees/loss_and_damage_executive_com mittee/items/10064.php. (2017).

13. Huq, S., Roberts, E. \& Fenton, A. Loss and damage. Nature Climate Change 3, 947-949 (2013).

14. Parker, H. R. et al. Stakeholder perceptions of event attribution in the loss and damage debate. Climate Policy 3062, 1-18 (2016).

15. Roberts, E. \& Pelling, M. Climate change-related loss and damage: translating the global policy agenda for national policy processes. Climate and Development, 114 (2016).

16. Huggel, C., Stone, D., Eicken, H. \& Hansen, G. Potential and limitations of the attribution of climate change impacts for informing loss and damage discussions and policies. Clim. Change (2015).

17. Surminski, S. \& Lopez, A. Concept of loss and damage of climate change a new challenge for climate decision-making? A climate science perspective. Climate and Development, 1-11 (2014).

18. Warner, K. \& Geest, K. V. Loss and damage from climate change: local level evidence from nine vulnerable countries. International Journal of Global Warming $\mathbf{5}$, 367-386 (2013).

19. http://loss-and-damage.net/download/6877.pdf.

20. Mechler, R. \& Schinko, T. Identifying the policy space for climate loss and damage. Science 354, 290 (2016). 
461 21. Schinko, T. \& Mechler, R. Applying Recent Insights From Climate Risk

462 Management to Operationalize the Loss and Damage Mechanism. Ecological

463 Economics 136, 296-298 (2017).

464 22. UNFCCC. A literature review on the topics in the context of thematic area 2 of the 465 work programme on loss and damage: A range of approaches to address loss and 466 damage associated with the adverse effects of climate change. UNFCCC Subsidiary 467 Body for Implementation (SBI), FCCC/SBI/2012/INF.14. 2014 (2012).

468 23. Mechler, R. \& Bouwer, L. M. Understanding trends and projections of disaster 469 losses and climate change: is vulnerability the missing link? Clim. Change (2014).

470 24. Roberts, E., Andrei, S., Huq, S. \& Flint, L. Resilience synergies in the post-2015 471 development agenda. Nature Climate Change 5, 1024-1025 (2015).

472 25. Hirsh, T. et al. Climate-Related Loss and Damage: Finding a Just Solution to the 473 Political Challenges. Available at: https://germanwatch. org/en/download/13036. pdf 474 (2015).

475 26. Mechler, R. \& Bouwer, L. M. Managing unnatural disaster risk from climate 476 extremes. Nature Climate â€। 4, 235-237 (2014).

477 27. Dow, K., Berkhout, F. \& Preston, B. L. Limits to adaptation. Nature Climate 478 Change 3, 305-307 (2013).

479 28. Klein, R. J. T. et al. in (eds Field, C. B. et al.) 899-943 (Cambridge University 480 Press, Cambridge, United Kingdom and New York, NY, USA, 2014).

481 29. UNFCCC. Decision 1/CP.16 The Cancun Agreements: Outcome of the work of 482 the Ad Hoc Working Group on Long-term Cooperative Action under the Convention. 483 (2011). 
484 30. Thompson, A. \& Otto, F. E. L. Ethical and normative implications of weather 485 event attribution for policy discussions concerning loss and damage. Clim. Change 486 (2015).

487 31. Wallimann-helmer, I. Justice for climate loss and damage. (2015).

488 32. Surminski, S., Bouwer, L. M. \& Linnerooth-Bayer, J. How insurance can support 489 climate resilience? Nature Climate Change 6, 333-334 (2016).

490 33. Otto, F. E. L. et al. Attribution of extreme weather events in Africa: a preliminary 491 exploration of the science and policy implications. Clim. Change (2015).

492 34. Parker, H. R. et al. Implications of event attribution for loss and damage policy. 493 Weather 70, 268-272 (2015).

494 35. Barnett, J., Tschakert, P., Head, L. \& Adger, W. N. A science of loss. Nature 495 Climate Change 6, 976-978 (2016).

496 36. Tschakert, P. et al. Climate change and loss, as if people mattered: values, 497 places, and experiences. Wiley Interdisciplinary Reviews: Climate Change (2017).

498 37. Hoffmaister, J. P., Talakai, M., Damptey, P. \& Barbosa, A. S. Warsaw 499 International Mechanism for loss and damage: Moving from polarizing discussions 500 towards addressing the emerging challenges faced by developing countries. 2014 501 (2014).

502 38. UNFCCC. Summary Information on the SCF Forum 2016. Available at: 503 http://unfccc.

504 int/files/cooperation_and_support/financial_mechanism/standing_committee/applicati 505 on/pdf/scf_forum_2016_information_summary_final2.pdf (2016). 
506 39. UNFCCC. Report of the Executive Committee of the Warsaw International

507 Mechanism for Loss and Damage associated with Climate Change

508 Impacts FCCC/SB/2014/4. Available at: http://unfccc.

509 int/resource/docs/2014/sb/eng/04. pdf (2014).

510 40. Boyd, E. \& Juhola, S. Stepping up to the climate change: Opportunities in re-

511 conceptualising development futures. Journal of International Development 21, $792-$

$512804(2009)$.

513

514

515

516

\section{Acknowledgements}

518 The researchers would like to thank all interviewees and stakeholder groups for

519 providing their time and insights, particularly committee members and observers at

520 the third meeting of the WIM ExCom, and participants of the Resilience Academy.

521 We also thank Alex Jones and Frances Wang for their work transcribing the

522 interviews. The research was facilitated by the Natural Environment Research

523 Council (NERC)-funded ACE-Africa project, with special contributions from the

524 University of Reading RETF, and Lund University.

525

526 Author contributions

527 E.B., R.A.J and R.G.J. designed the research project, conducted interviews,

528 analysed interview data, and wrote and revised the text. H.R.P. conducted interviews, 
529 contributed to data handling and developed of codes for analysis, and contributed to

530 the draft text. F.E.L.O. contributed by providing feedback on analysis, and

531 contributed to the draft text.

532

533 Competing financial interests

534 The authors declare no competing financial interests.

535

536 Figure Legends

537 Figure 1 The typology of four perspectives on loss and damage, (a) arranged

538 along an axis in terms of their characterisation of L\&D, and how far suggested

539 approaches to address L\&D are distinct from, or go beyond, existing adaptation

540 mechanisms (b) illustrating points of distinction between perspectives, and (c)

541 illustrating the extent to which each perspective in the typology is articulated by

542 stakeholder groups, and the extent to which UNFCCC mechanisms or agreements

543 encompass the perspectives.

544

545 Tables

546 Table 1 Illustrative words and phrases associated with each perspective, extracted 547 from interview transcripts (see methods for further detail).

548

\begin{tabular}{|l|l|}
\hline Perspective & Keywords \\
\hline $\begin{array}{l}\text { Adaptation } \\
\text { and } \\
\text { Mitigation }\end{array}$ & $\begin{array}{l}\text { prevent, avoid, proactive, reducing and reversing L\&D, } \\
\text { reducing and minimising, averting and reducing, minimising } \\
\text { risks, potential L\&D, potential impact, L\&D is under } \\
\text { adaptation, humanitarian response, unfortunate }\end{array}$ \\
\hline $\begin{array}{l}\text { Risk } \\
\text { Management }\end{array}$ & $\begin{array}{l}\text { climate risk management, comprehensive climate management, } \\
\text { holistic, total risk, risk layering, high level losses, changing risk } \\
\text { profile, evolving risk, socioeconomic thresholds, extreme events, }\end{array}$ \\
\hline
\end{tabular}




\begin{tabular}{|l|l|}
\hline & $\begin{array}{l}\text { downside risks, risk financing, financial instruments, private } \\
\text { sector, private sector engagement, risk management tools, } \\
\text { objective data driven solutions, operational solutions, early } \\
\text { intervention, risk reduction, early warning systems, risk pooling, } \\
\text { regional risk pool, contingency planning, post-disaster recovery, } \\
\text { resilience }\end{array}$ \\
\hline Limits to & $\begin{array}{l}\text { limits to adaptation, adaptation limits, adaptation constraints, } \\
\text { physical limits, social limits, beyond adaptation, residual loss \& } \\
\text { damage, residual impacts, migration, saline intrusion, agriculture, } \\
\text { non-economic losses, climate-related stressors, community-based, } \\
\text { values, livelihoods, resilience, vulnerable, poor and marginalised, } \\
\text { developing countries, micro insurance }\end{array}$ \\
\hline Existential & $\begin{array}{l}\text { residual harm, permanent, irreversible, irreplaceable, gone forever, } \\
\text { reality, it's happening, undeniable, unavoidable, nonmarket L\&D, } \\
\text { non-economic losses, values, sea level rise, islands, displacement, } \\
\text { refugees, loss of homeland, resettlement, reconstruction, } \\
\text { rehabilitation, restoration, compensation, ex-post, responsibility, } \\
\text { anthropogenic climate change, justice, liability, equity, human } \\
\text { rights, increase mitigation, more serious about mitigation }\end{array}$ \\
\hline
\end{tabular}


Table 2 Actions, research, and financing appropriate under each perspective, based on suggestions by interviewees and inference from their characterisation of $L \& D$

\begin{tabular}{|c|c|c|c|}
\hline Perspective & $\begin{array}{l}\text { Implications for } \\
\text { practice: How to } \\
\text { address L\&D through } \\
\text { action? }\end{array}$ & $\begin{array}{l}\text { Implications for } \\
\text { research: } \\
\text { How to improve } \\
\text { understanding of L\&D? }\end{array}$ & $\begin{array}{l}\text { Implications for } \\
\text { finance: How to } \\
\text { resource L\&D? }\end{array}$ \\
\hline $\begin{array}{l}\text { Adaptation } \\
\text { and } \\
\text { Mitigation }\end{array}$ & $\begin{array}{l}\text { Mitigation and } \\
\text { adaptation. }\end{array}$ & $\begin{array}{l}\text { All climate change } \\
\text { impacts are potential } \\
\text { L\&D, therefore } \\
\text { continuing research } \\
\text { efforts to understand } \\
\text { climate change impacts } \\
\text { (e.g. climate change risk } \\
\text { assessments for } \\
\text { adaptation, climate } \\
\text { services) are most } \\
\text { relevant. }\end{array}$ & $\begin{array}{l}\text { L\&D does not } \\
\text { require } \\
\text { additional } \\
\text { funding beyond } \\
\text { existing climate } \\
\text { finance. }\end{array}$ \\
\hline $\begin{array}{l}\text { Risk } \\
\text { Management }\end{array}$ & $\begin{array}{l}\text { Comprehensive risk } \\
\text { management. } \\
\text { Suggestions from } \\
\text { interviewees include: } \\
\text { insurance, insurance } \\
\text { pools, catastrophe } \\
\text { bonds, life insurance, } \\
\text { DRR, sovereign disaster } \\
\text { risk rating, climate } \\
\text { services and early } \\
\text { warning, engineering, } \\
\text { capacity building. }\end{array}$ & $\begin{array}{l}\text { Integration of disaster } \\
\text { risk assessment with } \\
\text { climate change risk } \\
\text { assessment. Analysis of } \\
\text { risk management tools } \\
\text { to identify gaps. }\end{array}$ & $\begin{array}{l}\text { Emphasis on } \\
\text { insurance } \\
\text { schemes and } \\
\text { private sector } \\
\text { finance. }\end{array}$ \\
\hline $\begin{array}{l}\text { Limits to } \\
\text { Adaptation }\end{array}$ & $\begin{array}{l}\text { Focus on options or } \\
\text { contingency plans for } \\
\text { vulnerable people. } \\
\text { Emphasis from } \\
\text { interviewees on: risk } \\
\text { transfer, social safety } \\
\text { nets, micro insurance, } \\
\text { innovations in } \\
\text { livelihoods (early } \\
\text { warning), and } \\
\text { participation. }\end{array}$ & $\begin{array}{l}\text { Analysis of what is } \\
\text { beyond adaptation. } \\
\text { Research with } \\
\text { vulnerable people to } \\
\text { identify limits, } \\
\text { monitoring and } \\
\text { evaluation (M\&E) for } \\
\text { adaptation, climate } \\
\text { change risk assessment } \\
\text { with estimate of } \\
\text { adaptation pathways } \\
\text { and limits. }\end{array}$ & $\begin{array}{l}\text { Emphasis is not } \\
\text { generally on } \\
\text { finance. }\end{array}$ \\
\hline Existential & $\begin{array}{l}\text { Focus on mitigation to } \\
\text { avoid L\&D, and ex-post } \\
\text { measures to address } \\
\text { loss, including: } \\
\text { compensation, } \\
\text { migration facilities, } \\
\text { homeland resettlement, } \\
\text { acknowledgement, } \\
\text { official apologies, } \\
\text { memorial, historical }\end{array}$ & $\begin{array}{l}\text { Analysis of probability } \\
\text { of, and vulnerability to, } \\
\text { permanent, irreversible, } \\
\text { long term, unavoidable } \\
\text { changes. Assessment of } \\
\text { L\&D, which has already } \\
\text { occurred. Research with } \\
\text { vulnerable people to } \\
\text { understand and } \\
\text { anticipate loss, }\end{array}$ & $\begin{array}{l}\text { Associated with } \\
\text { calls for } \\
\text { compensation, } \\
\text { but emphasis } \\
\text { that this is not } \\
\text { the only or even } \\
\text { most important } \\
\text { aspect of } \\
\text { addressing L\&D. }\end{array}$ \\
\hline
\end{tabular}




\begin{tabular}{|l|l|l|l|}
\hline preservation, & particularly non- \\
international litigation. & $\begin{array}{l}\text { economic loss (e.g. post } \\
\text { traumatic stresses } \\
\text { induced by events, loss } \\
\text { of identity or sense of } \\
\text { place). }\end{array}$ & \\
\hline
\end{tabular}

554

555

556 Methods

557 Summary

558 This is an empirical and impact-focused science-policy study of stakeholder

559 perspectives on $L \& D$, produced by a transdisciplinary team of researchers with

560 physical and social science expertise; emerging from a collaboration on a NERC

561 funded project about the attribution of extreme weather events in Africa (ACE-Africa).

562 The empirical results are based on 36 stakeholder interviews with 38 key

563 stakeholders, carried out in April-November 2015 by the co-authors. The primary

564 interview data have been triangulated with academic and grey literature, policy

565 documents, and participatory observations of meetings; and the results have been

566 refined through workshop engagement and feedback from key stakeholder groups,

567 and research project meetings. This research process involved sustained

568 engagement with core communities working on L\&D, also generating wider impact

569 through dialogue, building networks, and documenting the process to co-produce

570 new insights on this critical and controversial topic between 2015 and 2017. The

571 study has been designed to be politically impartial, but it is important to highlight this

572 kind of analysis cannot be completely objective or replicable, as is common in social

573 sciences $^{41}$.

574

575

576 Sampling strategy 
577 Potential interviewees were identified through stakeholder mapping to identify

578 influential and important actors in relation to L\&D. The core research team

579 constructed a list of researchers, practitioners, and policy-makers who were known to

580 meet at least one of the following criteria: they were involved in L\&D negotiations or

581 other L\&D activities under the UNFCCC including members of the ExCom; they had

582 attended UNFCCC L\&D meetings as observers; they had written papers of other

583 documents about L\&D; they were part of a L\&D network, including the L\&D network ${ }^{42}$,

584 or Asia Pacific Forum on Loss and Damage ${ }^{43}$; they were senior experts in adaptation,

585 disaster risk management, or UNFCCC processes. An effort was made to ensure

586 that this included experts from different types of institution (academic, non-

587 governmental organisations, international organisations, development banks,

588 consultancies, national government departments). Each interviewee was also asked

589 to recommend other interviewees following a snowball sampling technique ${ }^{44}$.This

590 technique allowed the study to limit bias by capturing the range of actors involved in

591 the issues but with different views ${ }^{45}$.This resulted in a list of over 100 potential

592 interviewees. Stakeholders from this list were prioritised using a carefully designed

593 set of criteria to encourage a balance of gender, expertise, and geographical area;

594 although the final sample of interviewees was also partly determined by availability

595 and willingness to interview. This resulted in a relatively large number of interviewees

596 from Europe, due in part to the location of the research team, and a relatively small

597 number of negotiators, possibly due to busy schedules and/or hesistancy to be

598 interviewed about this contentious topic.

599

600 The 38 interviewees included 23 men (60.5\%) and 15 women (39.5\%): and, based

601 on their current region, 63\% from Europe, 13\% from North America, 11\% from

602 Oceania, 8\% from Africa, and 5\% from Asia (although it is worth highlighting that

603 many of the relevant stakeholders travel frequently and may have affiliations or 
604 residences in more than one location). To give an insight into the type of 605 stakeholders interviewed, they were classified as primarily researchers (50\%), 606 practitioners (29\%), or negotiators (21\%), although many of those interviewed have 607 hybrid careers, with many researchers also being practitioners in adaptation, 608 development or DRR, and many negotiators also working as civil servants or 609 practitioners when they are not at UNFCCC meetings. Many of those classified as 610 researchers were interviewed in part due to their work supporting negotiators. A 611 subjective assessment of expertise of interviewees suggests that $71 \%$ had prior 612 expertise in L\&D, 55\% in adaptation, and 62\% in UNFCCC processes (many 613 obviously had expertise in all three of these key areas). Two of the interviewees 614 selected brought a colleague to the interview to help answer questions (bringing the 615 total to 38 interviewees and 36 interviews).

616

\section{Interview procedure}

618 The interviews were semi-structured, using a protocol interview guide (see 619 supplementary information), which included an opportunity for the interviewee to ask 620 questions and provide informed consent, and an assurance of confidentiality, 621 following ethical guidelines and approval from the University of Oxford Central 622 University Research Ethics Committee. Interviewees were asked about how they 623 would define L\&D, whether they had come across other perspectives on L\&D, the 624 distinction between adaptation and L\&D mechanisms, what actions should be taken 625 to address L\&D, scientific research which might be needed to support L\&D 626 mechanisms, and the importance of defining L\&D. Interviewees with prior experience 627 of UNFCCC negotiations were also asked about the emergence of L\&D within the 628 negotiations. The questions were tested and refined through two pilot interviews. 629 Interviews were conducted by one or two members of our team, in person, on skype, 630 or via telephone, and lasted between 15 and 90 minutes, depending on the 
631 availability of the interviewee, and the length of their answers. Where consent was

632 granted, interviewees were recorded, and transcribed by one of two research

633 assistants. Two of the interviews were not recorded, and instead the interviewer

634 wrote notes based on the interviewees responses. Following each interview, the

635 interviewer wrote some brief notes to comment on the tone of the interview and

636 inform consideration of reflexivity.

637

638

639 Data analysis and development of the typology

640 The interview transcripts were analysed using NVIVO, a qualitative data analysis

641 software. Coding was used to identify quotes under nine key themes, including the

642 distinction between adaptation and L\&D mechanisms, the relevance of climate

643 change, ex-ante and ex-post actions, finance, and justice (see supplementary

644 information). These themes were identified from the literature, and from observations

645 at L\&D discussions, as potential points of agreement and distinction in what signifies

646 L\&D. Some of the themes link directly to questions which were asked to participants

647 (for example they were asked several questions about the distinction between L\&D

648 and adaptation), and some of the themes were specifically not asked about in order

649 to gauge whether the interviewees would bring these issues up in discussion, and

650 therefore the amount of emphasis these themes had in their conceptualization of

651 L\&D (including finance and justice). The coding was conducted by reading the key

652 interview questions which were associated with the theme, and/or searching for key

653 words associated with that theme. Following the coding, the quotes identified under

654 each code and theme were used to determine the extent to which this theme

655 represented a point of distinction or agreement across the stakeholders.

656 
657 Then, in order to begin developing a typology of perspectives, each interview 658 transcript was considered in turn and the perspective of this interviewee was 659 summarised in line with the nine themes. After developing this summary for each 660 interviewee, it was possible to identify commonalities between some interviewees, 661 and to start to develop groupings of interviewees with similar perspectives. This was 662 not a simple process, and not all of the interviewees fit into these clusters. Some 663 interviewees had perspectives which seemed to span across multiple groups. Some 664 did not fit into any of the groupings, particularly those who didn't want to offer a 665 definition of L\&D, because they were highly skeptical of UNFCCC processes, 666 because they didn't feel they understood L\&D well enough to define it, or because 667 were aware of a lack of common understanding, many different perspectives, or 668 conflicting views, and therefore did not want to adopt any one definition themselves. 669 Nevertheless there were some interviewees with quite consistent perspectives that 670 were shared by a number of other stakeholders, making it possible to identify four 671 emerging clusters.

673 The grouping and clustering was conducted through iterative analysis, critical 674 reflection, and discussion amongst the core research team in a series of half-day 675 workshops. The coding themes were divided between two members of the team to 676 do analysis using NVIVO, and then results shared and discussed. Then the 677 summaries for each interview were written by one member of the team, these were 678 then discussed and refined through discussion. The groupings then emerged from 679 further discussion, which led to the drafting of a typology of four perspectives. There 680 were some remaining questions about these perspectives, which were then used to 681 check the coded quotes again and characterize how each perspective dealt with 682 each point of distinction and agreement (ultimately leading to Figure 1b). Following 683 this iterative analysis a typology of four perspectives had been developed, and each 
684 interviewee was categorised as either representing one perspective well, or spanning 685 multiple perspectives, or not fitting into any of the perspectives (but also not really 686 expressing clear or strong opinions about what L\&D signifies).

687

688 The typology was then reviewed based on an analysis of L\&D literature, including 689 UNFCCC texts, as well as reflections and observations from participation in 690 approximately 20 conferences, workshops, and meetings which included a focus on 691 L\&D.

692

693 In the social sciences typologies are a well-established analytical tool ${ }^{46}$. They are 694 used to form and refine concepts, draw out new dimensions, and create classification 695 types. Based on rigorous qualitative work typologies have potential conceptual power 696 to provide new insight into underlying dimensions of concepts ${ }^{46}$. There is, of course, 697 a certain amount of subjectivity involved in this analysis, and a different research 698 group might have developed a different typology of perspectives. The typology was 699 influenced by our own prior understandings and sustained engagement with 700 communities working on L\&D. We nevertheless endeavoured to accurately represent 701 the perspectives of the stakeholders we interviewed, and also checked our findings 702 with key experts to check whether our interpretation resonated with their own 703 experiences.

704

705 Stakeholder engagement to refine results

706 The initial typology was presented and tested in dialogue with ExCom members and 707 observers at the third meeting of the ExCom in April 2016, at the Adaptation Futures 708 conference in May 2016, and with scientific experts and practitioners working on 709 Loss and Damage at the Resilience Academy in September 2016. Experts were 
710 asked whether the typology resonated with their own perspectives and experience of

711 others' perspectives, whether we had missed anything, and whether they found the

712 typology helpful. These dialogues resulted in feedback which confirmed the

713 relevance of the typologies, and was used to refine their description, resulting in a set

714 of co-produced understandings, which have evolved through several iterations of a

715 policy brief ${ }^{47,48}$, and are presented here for the first time with evidence from

716 interviews and analysis of implications for research and policy.

717

718

719

Identification of keywords

720 The analysis of words and their associated meaning is a common tool in social

721 sciences. To identify the words and phrases in Table 1 we focused on stakeholder

722 interviews which resonated most strongly with each perspective, and then revisited

723 the transcripts and codes for these interviews to identify words which were used

724 frequently or emphasised.

725

726 Mapping stakeholders and political decisions onto the typology

727 After developing the typology of perspectives, and identifying whether each

728 interviewee represented one perspective well, or spanned multiple perspectives; we

729 then revisited the information we had collected about who these interviewees were:

730 what was their role, expertise, and affiliation. This is not straightforward as many of

731 the interviewees have somewhat hybrid roles. After gathering this information and

732 discussing it in another meeting of the core research team, we identified several key

733 stakeholder groups, including parties and observers to the UNFCCC for which we

734 could identify a stakeholder group, and the extent to which it adopted one or several

735 of the perspectives. This was supported by an analysis of literature, for example

736 including policy briefs by non-governmental organisations, which confirmed that 
737 climate justice campaigners were demonstrating an "Existential" perspective, and 738 submissions by parties to the UNFCCC, which confirm elements from range of the 739 perspectives are evident in the recent LDC and SIDS positions.

740

741 To map the WIM and Paris Agreement onto the typology, we analysed the relevant

742 decision texts to identify whether keywords from each perspective were present,

743 what was included and not included, and whether they were organised under

744 adaptation or not.

745

746

Data Availability

747 The interview data analysed in this study are confidential and therefore not publically

748 available. Some anonymised metadata, including statistics relating to regional and

749 gender balance of the interviewees, can be obtained from the corresponding author

750 on reasonable request.

751

752 Ethics statement

753 This work has been approved by the University of Oxford Central University

754 Research Ethics Committee. All interviewees provided informed consent.

755 Interviewees were assured that interview data would remain confidential, and

756 interviewees would remain anonymous.

757

758 References (Methods)

759 41. Ormston, R., Spencer, L., Barnard, M. \& Snape, D. in Qualitative research

760 practice: A guide for social science students and researchers (eds Ritchie, J., Lewis,

761 J., Nicholls, C. M. \& Ormston, R.) 1-26 (SAGE, 2014).

762

42. https://twitter.com/LossDamage. 
763 43. http://lossanddamageforum.org/.

764 44. Atkinson, R. \& Flint, R. in The SAGE encyclopedia of social science research

765 methods (eds Lewis-Beck, M. S., Bryman, A. \& Liao, T. F.) 1043-1044 (SAGE,

766 Thousand Oaks, CA, 2004).

767 45. Eisenhardt, K. M. \& Graebner, M. E. Theory building from cases: Opportunities

768 and challenges. Academy of management journal 50, 25-32 (2007).

769 46. Collier, D., LaPorte, J. \& Seawright, J. Putting typologies to work: Concept

770 formation, measurement, and analytic rigor. Political Research Quarterly 65, 217-232

771 (2012).

772 47. Boyd, E., James, R. \& Jones, R. Policy Brief: Typologies of Loss and Damage

773 and Associated Actions. (2016). Available at:

774 http://www.eci.ox.ac.uk/publications/policy-brief-

775 pdf/160608 Typologies ExCom3Update Final.pdf

776 48. Boyd, E., James, R. \& Jones, R. Policy Brief: A spectrum of views on Loss and

777 Damage. (2016). Available at: http://www.eci.ox.ac.uk/publications/161101.pdf

778 
a

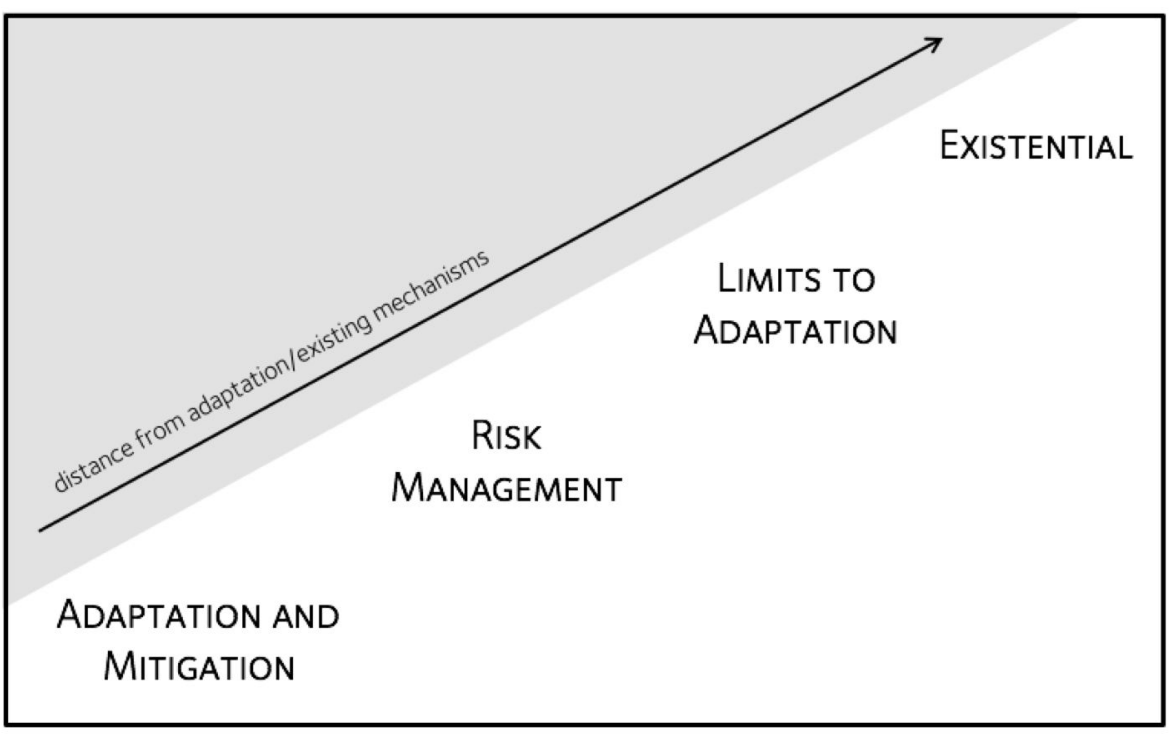

b

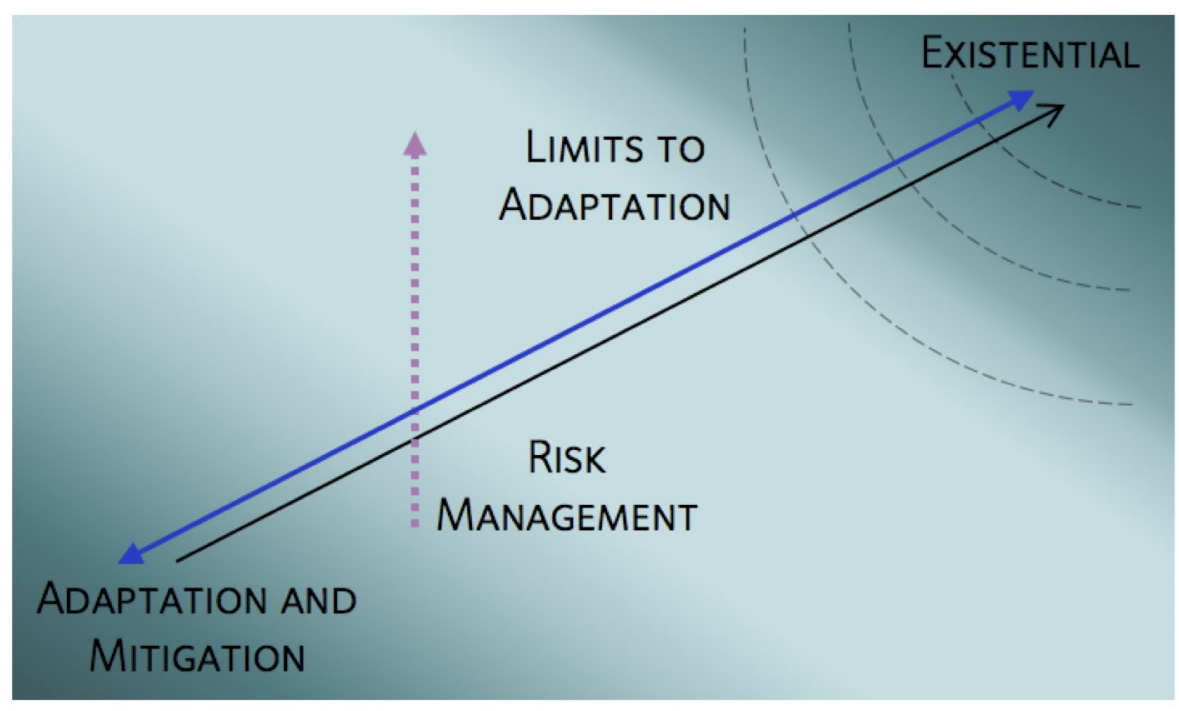

C

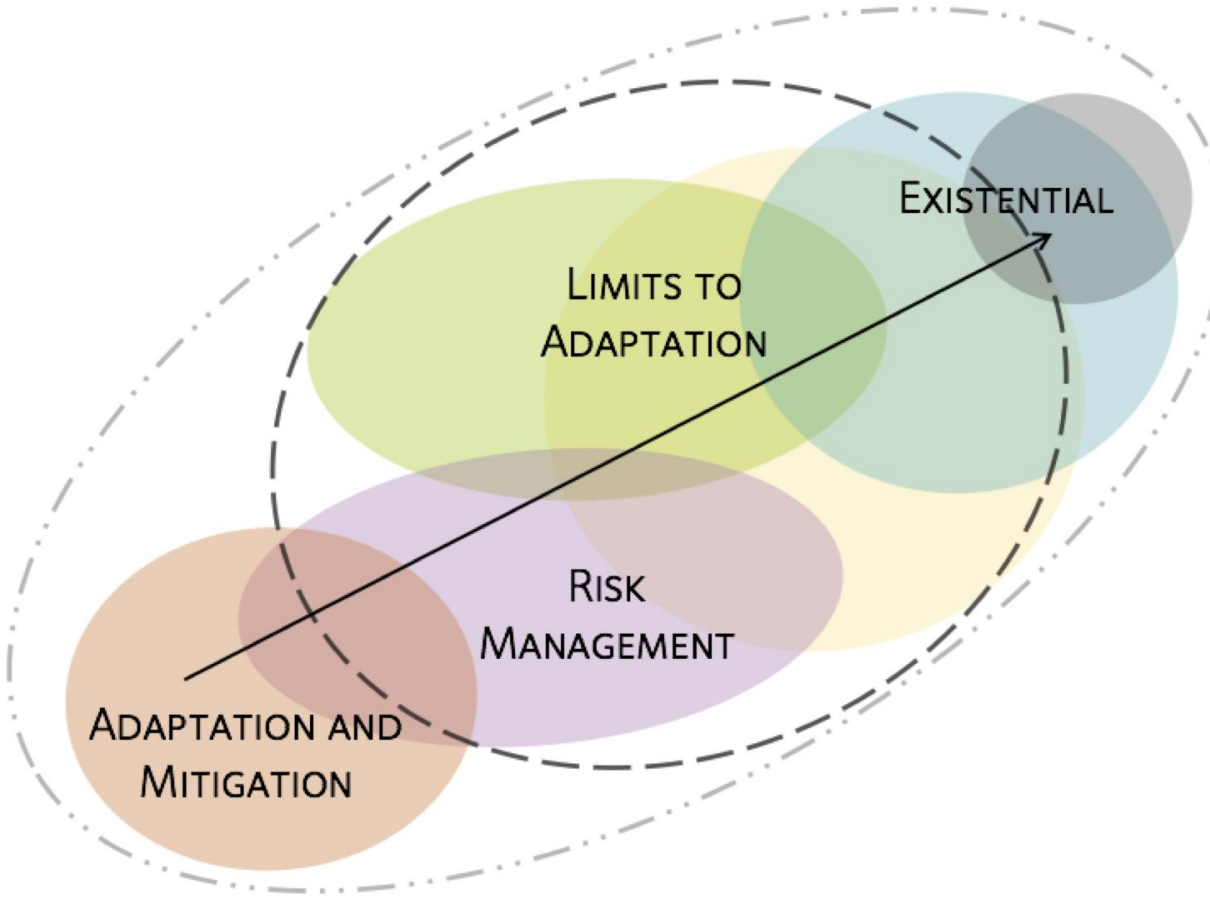

Points of Distinction
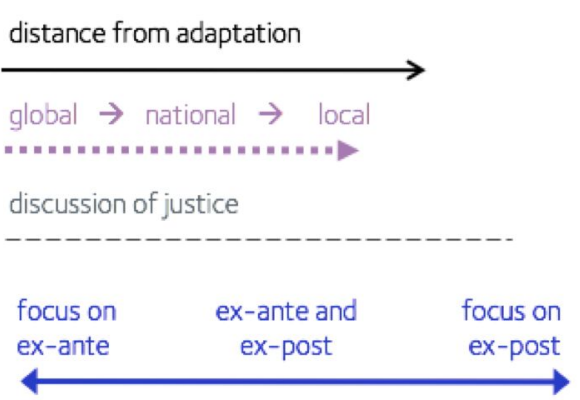

focus on

Parties

developed countries

SIDS

LDCs

Observers

climate justice campaigners

adaptation experts

disaster risk reduction experts

WIM

Paris Agreement 